\title{
Atmospheric forcing of sea ice anomalies in the Ross Sea polynya region
}

\author{
Ethan R. Dale ${ }^{1,2}$, Adrian J. McDonald ${ }^{1}$, Jack H. J. Coggins ${ }^{1}$, and Wolfgang Rack ${ }^{2}$ \\ ${ }^{1}$ Department of Physics and Astronomy, University of Canterbury, Christchurch, New Zealand \\ ${ }^{2}$ Gateway Antarctica, University of Canterbury, Christchurch, New Zealand \\ Correspondence to: Ethan R. Dale (ethan.dale@pg.canterbury.ac.nz)
}

Received: 12 April 2016 - Published in The Cryosphere Discuss.: 2 May 2016

Revised: 30 November 2016 - Accepted: 13 December 2016 - Published: 27 January 2017

\begin{abstract}
We investigate the impacts of strong wind events on the sea ice concentration within the Ross Sea polynya (RSP), which may have consequences on sea ice formation. Bootstrap sea ice concentration (SIC) measurements derived from satellite SSM/I brightness temperatures are correlated with surface winds and temperatures from Ross Ice Shelf automatic weather stations (AWSs) and weather models (ERAInterim). Daily data in the austral winter period were used to classify characteristic weather regimes based on the percentiles of wind speed. For each regime a composite of a SIC anomaly was formed for the entire Ross Sea region and we found that persistent weak winds near the edge of the Ross Ice Shelf are generally associated with positive SIC anomalies in the Ross Sea polynya and vice versa. By analyzing sea ice motion vectors derived from the SSM/I brightness temperatures we find significant sea ice motion anomalies throughout the Ross Sea during strong wind events, which persist for several days after a strong wind event has ended. Strong, negative correlations are found between SIC and AWS wind speed within the RSP indicating that strong winds cause significant advection of sea ice in the region. We were able to partially recreate these correlations using colocated, modeled ERA-Interim wind speeds. However, large AWS and model differences are observed in the vicinity of Ross Island, where ERA-Interim underestimates wind speeds by a factor of 1.7 resulting in a significant misrepresentation of RSP processes in this area based on model data. Thus, the cross-correlation functions produced by compositing based on ERA-Interim wind speeds differed significantly from those produced with AWS wind speeds. In general the rapid decrease in SIC during a strong wind event is followed by a more gradual recovery in SIC. The SIC recovery contin-
\end{abstract}

ues over a time period greater than the average persistence of strong wind events and sea ice motion anomalies. This suggests that sea ice recovery occurs through thermodynamic rather than dynamic processes.

\section{Introduction}

Throughout the satellite observation era the total winter sea ice cover in the Southern Ocean has followed a well established increasing trend, a process that is mainly driven by significant sea ice expansion in the Ross Sea (Comiso and Nishio, 2008; Turner et al., 2009, 2015; Holland, 2014). However, there is still uncertainty about the mechanisms that have driven this change. The central aim of this work is to study how the variability of strong southerly winds over the western Ross Ice Shelf impacts sea ice concentration (SIC) in the region near the Ross Sea polynya (RSP). A polynya is an area of open water or decreased SIC surrounded by either concentrated sea ice or land ice. Due to the increased oceanto-atmosphere heat flux within these regions, polynyas are areas of high sea ice production (Tamura et al., 2008). The Ross Sea polynya is a large polynya that regularly forms near the northwestern edge of the Ross Ice Shelf as a result of persistent offshore winds.

This work builds on previous studies, such as those by Bromwich et al. (1998), Kwok et al. (2007), Reddy et al. (2007), Comiso et al. (2011), Drucker et al. (2011), Holland and Kwok (2012), and Turner et al. (2015), who have shown that the Ross Sea polynya and the related atmospheric forcing plays an important role in sea ice production. For example, Drucker et al. (2011) estimate that $20-50 \%$ of the sea 
ice production in the Ross Sea occurs in the RSP and that the increase in sea ice extent in the Ross Sea region is related to the changes in wind forcing. Bromwich et al. (1998) compare AWS wind speeds and temperatures with SIC derived from Special Sensor Microwave/Imager (SSM/I) data within the RSP. Bromwich et al. (1998) found that $25 \%$ of polynya SIC variance within the RSP can be explained by wind and temperature variations observed at Ferrell AWS.

Coastal polynyas, such as the RSP, are driven by sea ice export from the coast, with sea ice drift being controlled by both oceanographic and atmospheric forcings. Ice in free drift will have a velocity equal to that of the local ocean current plus some component due to the effect of wind stress (Holland and Kwok, 2012). This wind component will fall to the left of the wind vector in the Southern Hemisphere and has a magnitude of up to about $2 \%$ of the local wind speed (Brümmer et al., 2008). In consolidated ice, internal stresses will oppose the geostrophic wind and therefore decrease ice drift velocity (Brümmer and Hoeber, 1999). Holland and Kwok (2012) used sea ice motion data and reanalysis wind fields to show that wind-driven changes in ice advection are the dominant drivers of SIC trends around much of West Antarctica. Also, wind-driven thermodynamic changes play a large role in coastal regions of the Atlantic sector (Kong Håkon VII Sea) where autumn SIC trends oppose the near-surface wind variations.

As sea ice production occurs within the RSP brine, rejection occurs, forming negatively buoyant dense water. This leads to the formation of Antarctic bottom water (AABW) (Whitworth and Orsi, 2006). AABW formation is suggested as a major sink for $\mathrm{CO}_{2}$ and heat and is a driver of global ocean circulations (Ohshima et al., 2013). A change in the rate of sea ice production within the RSP and therefore the rate of $\mathrm{AABW}$ production could have significant effect on the global ocean circulation.

Previous studies were constrained by a lack of detailed meteorological measurements. The weather patterns over the Ross Sea contain many small-scale features that are governed by the topography of the area. Thus, current models such as the Antarctic Mesoscale Prediction System (AMPS; Powers et al., 2012) are unable to resolve many of these features (Coggins et al., 2013; Jolly et al., 2016). This means that understanding the direct influence of strong winds on the formation of the RSP, a region of major sea ice production, has been limited. The analysis of the seasonal patterns of Antarctic sea ice growth and decline and its interannual variability is complicated by the fact that they depend on a number of atmospheric and oceanic forcings that occur at a wide range of timescales. In particular, SIC is influenced by both atmospheric and oceanic factors, including the strength of nearsurface winds, air temperature, ocean currents, ocean temperature and salinity of the ocean (Bintanja et al., 2013; Holland and Kwok, 2012; Holland, 2014; Turner et al., 2015).

The primary synoptic-scale atmospheric variations affecting sea ice include the overall magnitude of the geostrophic wind (Sen Gupta and England, 2006), the localized zonal and meridional wind anomalies (Stammerjohn et al., 2008; Kwok and Comiso, 2002; Sen Gupta and England, 2006; Turner et al., 2009; Holland and Kwok, 2012), surface air temperature anomalies (Sen Gupta and England, 2006; Kwok and Comiso, 2002), and variations in energy fluxes between the atmosphere-ocean-sea ice systems. Geostrophic winds are also central to describing the variations in localized Ekman transport patterns within the ocean. Specifically, Stammerjohn et al. (2008) identified that enhanced Westerlies throughout the 1990s in the western Ross Sea caused a more persistent northward Ekman sea ice drift, which affected the seasonal ice extent of the region by causing earlier ice advance and later ice retreat.

In this study, we investigate winter in situ measurements from weather stations directly upwind of the Ross Sea polynya in relation to satellite measurements of sea ice cover in order to better understand the timescales over which surface wind impacts on sea ice drift and potential sea ice formation. We do this in comparison with winds from a lowresolution reanalysis model (ERA-Interim. Dee et al., 2011) in order to find out to what extent simulated wind fields in the region can reproduce the statistical relationship and dependence between weather and sea ice anomalies. This work therefore has a wider relevance given that atmospheric circulation changes in the Ross Sea may explain a significant portion of the climate variation in the region and particularly increases in sea ice extent and the northward drift of sea ice (Holland and Kwok, 2012; Nicolas and Bromwich, 2014).

\section{Data and methods}

We utilize both basic bootstrap algorithm and AMSR-E bootstrap algorithm sea ice concentration (SIC) data (henceforth "bootstrap" collectively) provided by the National Snow and Ice Data Center (NSIDC) (Comiso, 2000; Maslanik and Stroeve, 2004). Bootstrap SIC is available on a daily basis sampled on a $25 \mathrm{~km}$ by $25 \mathrm{~km}$ grid since 1987 and every other day prior to this date (starting in 1978). Daily averages of SIC swath data are provided by NSIDC; these were assumed to be centered around midday with measurement spread $12 \mathrm{~h}$ before and after the reported time. We obtain $2 \mathrm{~m}$ wind speed and $2 \mathrm{~m}$ temperature data measured at the Laurie II automatic weather station (AWS), located at $77.52^{\circ} \mathrm{S}, 170.81^{\circ} \mathrm{E}$, provided by the University of Wisconsin-Madison Automatic Weather Station Program detailed in Lazzara et al. (2012). The Laurie II station has been providing data at $10 \mathrm{~min}$ temporal resolution since February 2000. In this study we focus on output from the Laurie II station because of its long continuous record and proximity to the RSP. The analysis presented has also been completed for a number of other stations, including Vito, Emilia and Ferrell stations, and these results remain rather similar. 


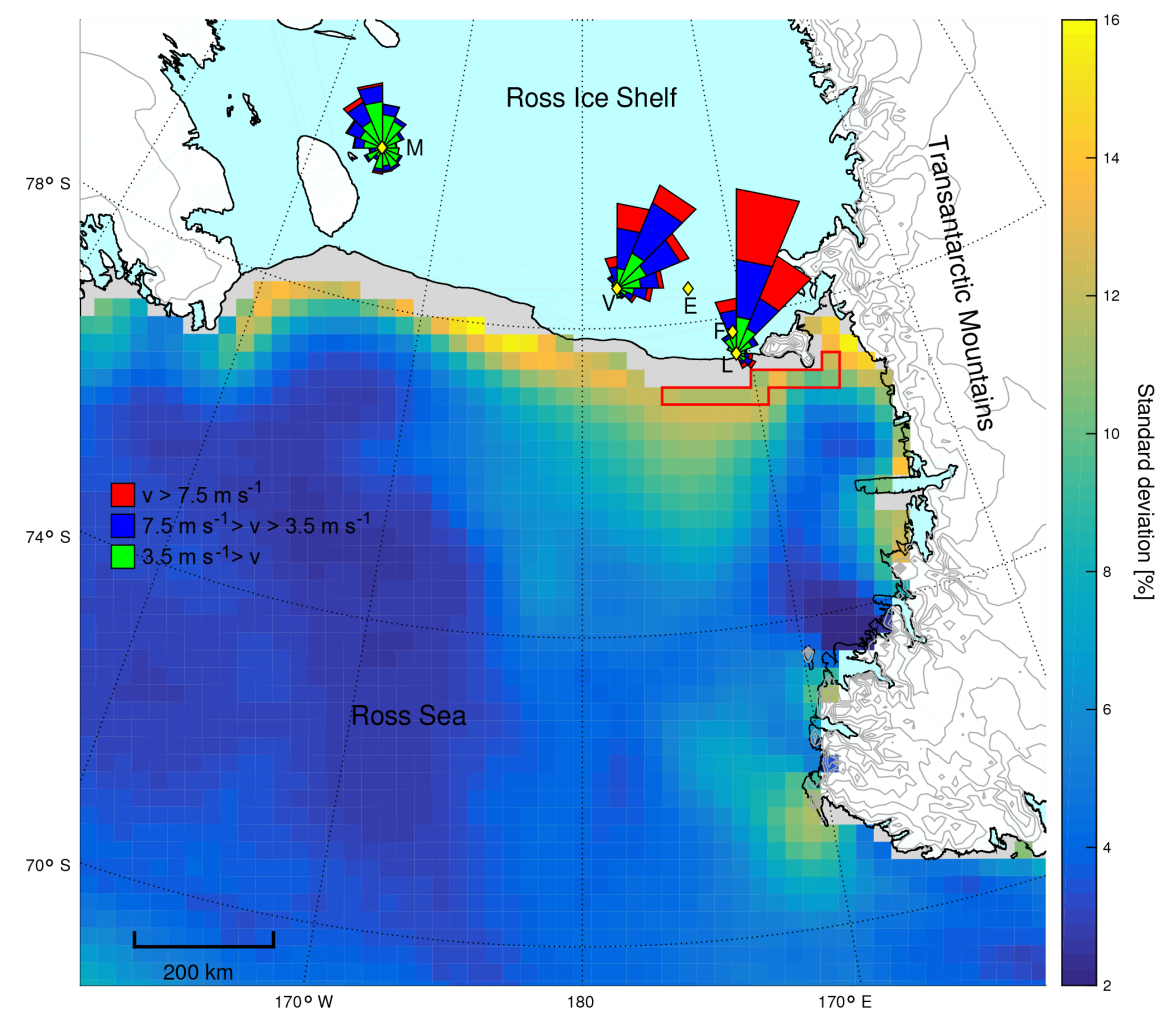

Figure 1. Map of Ross Sea region, grey contour lines indicate topography at $500 \mathrm{~m}$ intervals (Liu et al., 2001). The color scale indicates the standard deviation of bootstrap SIC for 20 April-1 November 1979-2014. Yellow diamonds indicate the positions of Margaret, Vito, Emilia, Ferrell and Laurie II AWS sites, labeled M, V, E, F and L, respectively. Wind roses for Margaret, Vito and Laurie II are included. The green, blue and red colors indicate the low, medium and high wind speeds based on the $33 \mathrm{rd}$ and 66 th percentile wind speeds $\left(3.5\right.$ and $\left.7.5 \mathrm{~ms}^{-1}\right)$ as measured at Laurie II. The red line outline indicates the region discussed in Sect. 2.

Figure 1 shows the standard deviation of SIC, calculated from the daily variation from the long-term winter mean of bootstrap SIC data over the period 20 April until the 1 November for the years 1979 until 2014. This period was chosen to exclude the annual break out of sea ice to minimize variability not associated with day-to-day polynya activity. Coastal pixels often display a large variability, for example the area longitude 170 and $180^{\circ}$ E extending several hundred kilometers offshore. The orientation of this area corresponds well with both the dominant wind directions observed at the Laurie II AWS site and the location of the RSP as identified in Nakata et al. (2015) amongst others. Large deviations from the mean are due to the high variability in SIC within the polynya, as displayed in Fig. 2.

For our analysis we define a region comprised of pixels adjacent to the bootstrap land mask and $10^{\circ}$ wide in longitude centered on the Laurie II AWS site, identified in red in Fig. 1. This gives a $25 \mathrm{~km}$ by $250 \mathrm{~km}$ region close to the Ross Ice Shelf and Ross Island, colocated within the area where the Ross Sea polynya can be observed. The wind roses in Fig. 1 display the distribution of wind vectors observed at various AWS sites (Margaret, Vito and Laurie II).
We derive sea ice motion vectors from the National Snow and Ice Data Center's $12.5 \mathrm{~km}$ resolution polar stereographic gridded brightness temperatures, retrieved from the special sensor microwave/imager and special sensor microwave imager/sounder (SSMIS) instruments (Maslanik and Stroeve, 2004). Daily averages are available from July 1987 to December 2015. We utilize the vertical and horizontal polarizations of the $85.5 \mathrm{GHz}$ channel from 1987 to 2009 and the $91.7 \mathrm{GHz}$ channel from 2010 onwards.

Following multiple authors (Emery et al., 1997; Heil et al., 2006; Holland and Kwok, 2012), we estimate ice motion via a maximum cross-correlation method. We track $9 \times 9$ grids of stereographic cells $(112.5 \times 112.5 \mathrm{~km})$ over a radius of eight grid cells $(100 \mathrm{~km})$. The search radius provides an upper limit for ice velocity of approximately $1.2 \mathrm{~ms}^{-1}$, defining a physically plausible range (Heil et al., 2006).

The cross-correlation method proceeds by comparing consecutive daily averages of brightness temperature data. For each day, brightness temperatures in a particular grid are correlated against those in the surrounding grids on the subsequent day. The sea ice is assumed to have moved to the grid with the highest correlation. A correlation threshold of 0.7 was chosen to limit erroneous designations. Our method 

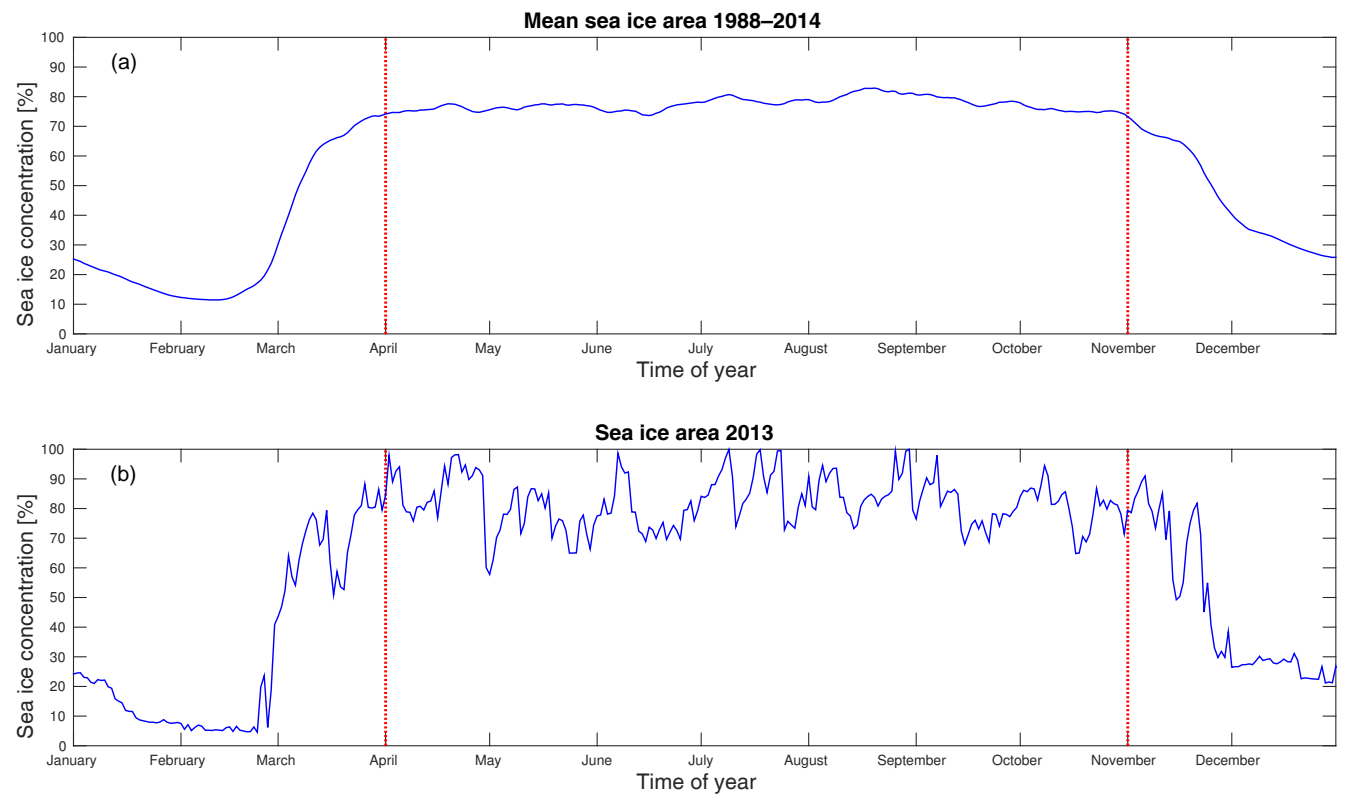

Figure 2. (a) Mean SIC within RSP north of the Laurie AWS from the region identified in Fig. 1. (b) SIC during 2013, highlighting day-to-day variability. Red dotted lines identify the period from April to October used in this study.

uses the maximum correlation from both the horizontal and vertical polarizations. From the resulting displacement and time period the ice velocity was estimated. We subsequently smoothed the gridded velocities to a $25 \mathrm{~km}$ stereographic grid.

Using this simple method, fast small-scale motions as well as rotations and divergence of the ice pack are not resolved. Furthermore, motion in coastal areas is likely to be less accurate due to the difficulties in applying the method to incomplete grids. Brightness temperature-derived motions are considered inaccurate outside of the winter season due to surface melt and high levels of atmospheric water vapor (Emery et al., 1997; Holland and Kwok, 2012). Hence, we restrict our analysis of sea ice motions to the cold months of April to October.

We compare winds observed at the AWS sites with $10 \mathrm{~m}$ winds of the ERA-interim meteorological reanalysis model (Dee et al., 2011). The model output is available on a $0.75^{\circ} \times 0.75^{\circ}$ grid at a $6 \mathrm{~h}$ temporal resolution running from late 1979 until present. Although AMPS provides higherresolution weather data, ERA-Interim was used due to its temporal consistency and data set spanning the AWS period. ERA-interim does not assimilate wind speed measurements over land (including ice shelves) and is therefore independent from AWS measurements. For comparison of AWS and ERA-interim wind data, virtual AWSs were created by interpolating the wind speed from the ERA-Interim grid to the location of the AWS sites using a bilinear interpolation.

\section{Results}

\subsection{SIC within the Ross Sea polynya}

Figure 2a shows the mean SIC within the coastal area identified in Fig. 1 averaged over the period 1988 to 2014. Throughout the winter period, defined between 1 April and 1 November in this study, the total SIC within this area is relatively constant. Outside this period we observe a gradual decrease in SIC from November until a minimum is reached in mid-February, followed by a more rapid increase in SIC in early March. For the remainder of this analysis we will only consider the period from April to October to remove the effects of summer melt and to avoid periods with low SIC and large gradients in SIC. Figure $2 b$ shows the daily SIC for the same area derived from data in 2013 to show the high degree of variability in the SIC in this region; these results resemble a previous analysis reported in Bromwich et al. (1998). The large day-to-day variability between April and October (Fig. 2b) is likely to be associated with polynya processes. The sawtooth features observed in this specific year, for example around $1 \mathrm{May}$, are common features and illustrate that decreases in SIC generally occur more rapidly than the following increases in SIC, a point that will be supported by later analysis.

\subsection{Inter-comparison of AWS and ERA-Interim wind speeds}

The wind climatology of the region, derived from AWS data, is represented by wind roses in Fig. 1. Wind roses are angular 
histograms indicating prevailing winds; the colors indicate the distribution of wind speed in each angular sector. Inspection of the wind rose closest to Ross Island (Laurie II) shows that the wind in this region is dominated by strong southerly flows. These strong southerly flows are also an important feature of the wind distribution at the other AWS sites displayed in Fig. 1 but are not observed as frequently. However, as identified previously, the results presented do not change appreciably if data from other AWS sites in the northwestern corner of the Ross Ice Shelf are utilized.

The wind speeds measured at four AWSs, Laurie II, Ferrell, Emilia and Vito, were compared to the virtual sites interpolated from the ERA-Interim model grid. Scalar wind speeds at Laurie II, Ferrell and Emilia correlated well with $R^{2}>0.75$, while Vito was found to have a weaker correlation of $R^{2}=0.55$. Inspection of ERA-Interim and AWS wind roses revealed no significant directional bias between the two data sets. However, when linear least square fits between the model and the Laurie and Ferrell AWS winds were applied, slopes of 1.70 and 1.52 , respectively, were found, indicating that at these sites ERA-Interim generates significantly weaker wind speeds than measured by the AWS. Scale factors measured at Emilia and Vito were 1.06 and 0.96, respectively, indicating a better agreement between the AWS and ERA-Interim wind speeds at these sites. Laurie and Ferrell are located 36 and $57 \mathrm{~km}$ from Cape Crozier (at the eastern end of Ross Island), while Emilia and Vito lie 140 and $223 \mathrm{~km}$ east of Ross Island. Thus, the differences observed are likely linked to the local topography that is not well represented in the ERA-Interim reanalysis. Recent work by Jolly et al. (2016) comparing AWS observations with the Antarctic Mesoscale Prediction System output (a much higher-resolution atmospheric model) also identifies that the effect of topography in the region can not be reproduced by the model (Powers et al., 2012). It should also be noted that ERA-Interim does not assimilate wind speed measurements over land and so the two data sets are independent (Dee et al., 2011).

\subsection{Correlations between SIC and AWS measurements}

Cross-correlation functions (CCFs) between the time series of SIC within the region in Fig. 1 and both wind speeds and temperatures measured at the Laurie II AWS site were calculated for the 2000-2014 period. For comparison with daily bootstrap SIC data, $24 \mathrm{~h}$ running means of the $10 \mathrm{~min}$ AWS measurements were used. Although SIC data were only available on a $24 \mathrm{~h}$ resolution, wind data were available at a $10 \mathrm{~min}$ resolution. By varying the time lag between these two time series and calculating the Pearson correlation coefficient for each lag, CCFs were able to be calculated at a $10 \mathrm{~min}$ time resolution. The bootstrap SIC is derived from $24 \mathrm{~h}$ binned brightness temperatures and we compared these with the $24 \mathrm{~h}$ rolling mean of AWS data. The resulting correlation functions will be blurred over a $24 \mathrm{~h}$ period. The CCF between the time series of SIC and both scalar wind speeds and temperatures measured at the Laurie II AWS site are shown in Fig. 4.

In Fig. 4a we find a strong negative correlation between SIC and wind speed, with the maximum magnitude correlation occurring after a $12 \mathrm{~h}$ time lag. The minimum is preceded by a rapid decrease and followed by a more gradual increase in correlation with respective $e$-folding times of -48 and $100 \mathrm{~h}$. This indicates that during high-wind events the SIC in the RSP area is generally low. The difference in the decrease and increase $e$-folding times suggests that the two changes are controlled by different processes. For example, we expect that the decrease in SIC is dominated by more rapid northward advection, while the increase in SIC during sea ice formation is dominated by slower ice formation. This interpretation is supported by the recent analysis detailed in Nakata et al. (2015), which used a simplified model to understand polynya changes.

Laurie II is located about $50 \mathrm{~km}$ south of the region used for the SIC analysis. A change of predominantly southerly winds (Parish and Bromwich, 2007) is first observed upwind at Laurie II before the signal propagates to the RSP downwind. Wind blowing at $5 \mathrm{~ms}^{-1}$ would take about $3 \mathrm{~h}$ to travel the distance, meaning the $12 \mathrm{~h}$ delay observed cannot be entirely explained by this process. Another contributing factor is that the region used for calculating the SIC is not directly adjacent to the northern edge of the RIS and an area of sea ice may exist south of the studied polynya area. If a northward advection of sea ice occurs, the ice advected from the region will be replaced by ice in the unobserved region between the Ross Ice Shelf and the region specified in Fig. 1. This could allow advection of sea ice to occur for a short period of time without a decrease in SIC occurring, causing the minimum in sea ice to occur several hours after a significant increase in wind speed. In addition, as a strong wind event progresses, the sea ice will ridge and raft upon itself, causing the surface roughness of the ice to increase. We speculate that this will make the ice slightly more susceptible to the wind stress (Mårtensson et al., 2012). As the SIC decreases, internal stresses prohibiting motion will decrease, allowing advection to become more significant. These effects will cause the minimum SIC to occur slightly after the time of maximum wind speed and are likely causes of the location of the minimum correlation between SIC and wind occurring at approximately a $12 \mathrm{~h}$ delay, though the collection of swath data also introduces some uncertainty in the exact timing. Wind speeds in the area autocorrelate with an $e$-folding time of $36 \mathrm{~h}$ (Fig. 4a), which explains the significant correlations in the CCF between AWS wind speed and SIC at negative delay. The $e$-folding time for the decrease in this CCF is $-48 \mathrm{~h}$ and the extrema occurs at a delay of $12 \mathrm{~h}$ corresponding with the $36 \mathrm{~h} e$-folding time for AWS wind speeds.

The CCF of temperature versus sea ice concentration also shows a significant negative correlation with the minimum occurring at a $0 \mathrm{~h}$ delay (Fig. $4 \mathrm{~b}$ ). The $e$-folding times for 


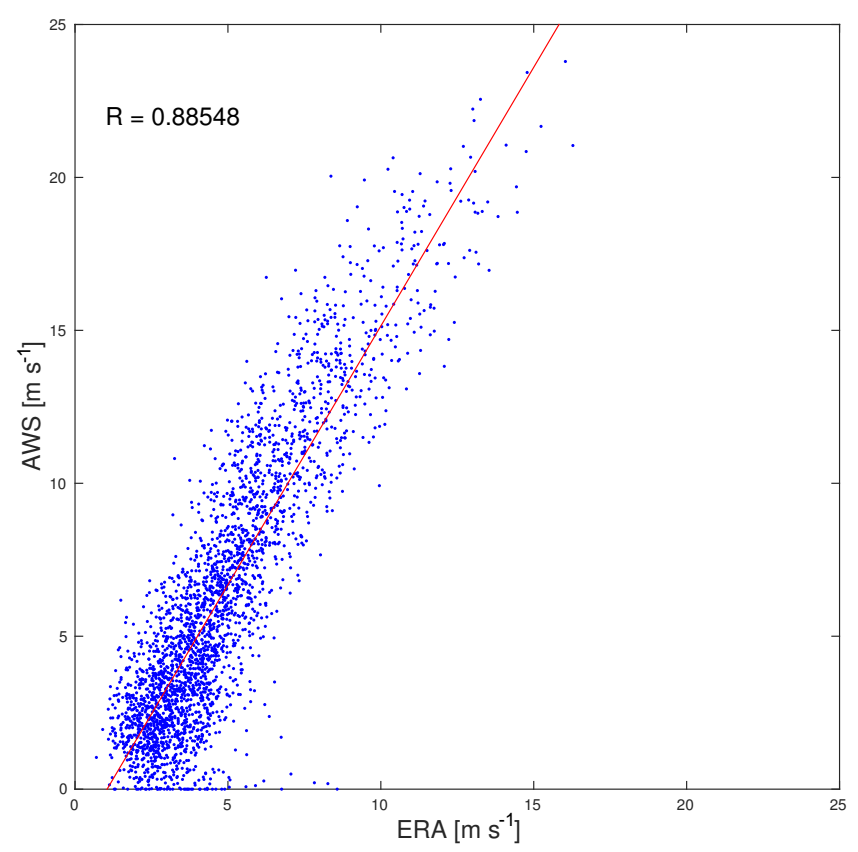

Figure 3. Scatter plot of $24 \mathrm{~h}$ mean wind speed for winter 20002014, measured by Laurie II AWS against that of ERA-Interim. The red line indicates the linear least squares fit.

this curve are -120 and $170 \mathrm{~h}$ for the decreasing and increasing periods, respectively. These values are both similar to the autocorrelation $e$-folding time for temperatures measured at Laurie II of $150 \mathrm{~h}$. As a strong wind event progresses and SIC decreases, the heat flux from the ocean to the atmosphere will increase, causing production of new sea ice through freezing. The rate of freezing of open water will depend on the temperature differential between the ocean and the atmosphere, potentially explaining the significant correlations observed. Significant positive correlations can also be found between the temperature and wind speeds measured at the Laurie II station (Fig. 4b), which we interpret as at least partially the cause of the correlation between temperature and SIC. In addition, work detailed in Coggins et al. (2014) also suggests that strong wind events, particularly Ross Ice Shelf airstream (RAS) events (Parish et al., 2006), are related to warm surface temperature anomalies. This is due to changes in low-level stratification. During periods of low winds, a layer of cool, dense air is observed near the surface, while during higher wind speeds the warmer overlying layer is mixed down toward the surface. Adiabatic warming linked to air traversing the Transantarctic Mountains also contributes to this temperature anomaly. However, given that the correlation between temperature and wind speed at Laurie II is 0.5 at zero hours and the correlation between temperature and SIC is -0.65 , there must be some other causal link between temperature and SIC. We suggest that this is likely due to a more gradual rate of freezing of open water during periods of higher air temperatures (effectively a smaller temperature differential between ocean and air temperatures impacting the sensible heat flux).

\subsection{Comparison of ERA-Interim and AWS CCFs}

CCFs were also produced using the ERA-Interim virtual AWSs in the same manner, although at a $6 \mathrm{~h}$ temporal resolution dictated by the temporal resolution of the ERA-Interim output. We found that both the wind speed, SIC and wind speed autocorrelation were very similar to those found using the AWS wind speeds (Fig. 2a). This is not surprising since the ERA-Interim wind speeds correlate well with those of AWS at Laurie. The CCF of temperature versus SIC, CCF of temperature versus wind speed and the temperature autocorrelation from the ERA-Interim output have similar forms to the relationships derived using AWS data but are generally smoother and the magnitude of the largest correlations are generally smaller. The temperature autocorrelation curve shows that ERA-interim predicts more persistent temperatures than the Laurie II AWS measures. This likely indicates that high-frequency temperature fluctuations are not accurately modeled within ERA-interim. The ERA-Interim CCF of wind speed versus temperature shows weaker correlation for delays less than $24 \mathrm{~h}$, with the difference becoming negligible around $-72 \mathrm{~h}$. This probably indicates that the warming of the air due to mixing, suggested in Coggins et al. (2013) and other studies, caused by strong winds is underestimated in ERA-interim. These effects likely cause the small differences between the ERA-interim temperature and SIC correlations and the correlations of the Laurie II AWS.

Cross-correlation curves for SIC and wind speed measured at Laurie II AWS site and wind speed hindcast from the ERAInterim virtual station are now examined (Fig. 5a-c). The daily mean wind speeds measured at Laurie II were categorized into low, medium and high-wind events based on 33rd and 66th percentile AWS wind speeds measured at Laurie II ( 3.5 and $7.6 \mathrm{~ms}^{-1}$, respectively). Wind direction was not considered in this classification because of the predominance of southerly flows at the site. CCFs for SIC with wind speed were calculated only for periods when the mean wind speed during $\mathrm{a}-12$ to $+12 \mathrm{~h}$ period was within one of the three categories (Fig. 5). Autocorrelation curves for the wind in each of these three cases were also calculated to allow the persistence of each of the three strengths of wind speed events to be identified. The AWS medium-wind case autocorrelation curve (Fig. 5b) shows considerably lower persistence than either of the extreme cases, indicating that this is a transition state that occurs frequently for short periods. The high-wind case (Fig. 5c) shows a CCF very similar to that of all cases (Fig. $4 \mathrm{~b}$ ), excluding the period from -36 to $+12 \mathrm{~h}$ delay.

The force exerted on sea ice is proportional to the wind stress, which is proportional to the square of the wind speed. This will cause the winds within the high-wind case to have a greater impact on sea ice motion than those of the lower cases. All cases show negative correlations between SIC and 

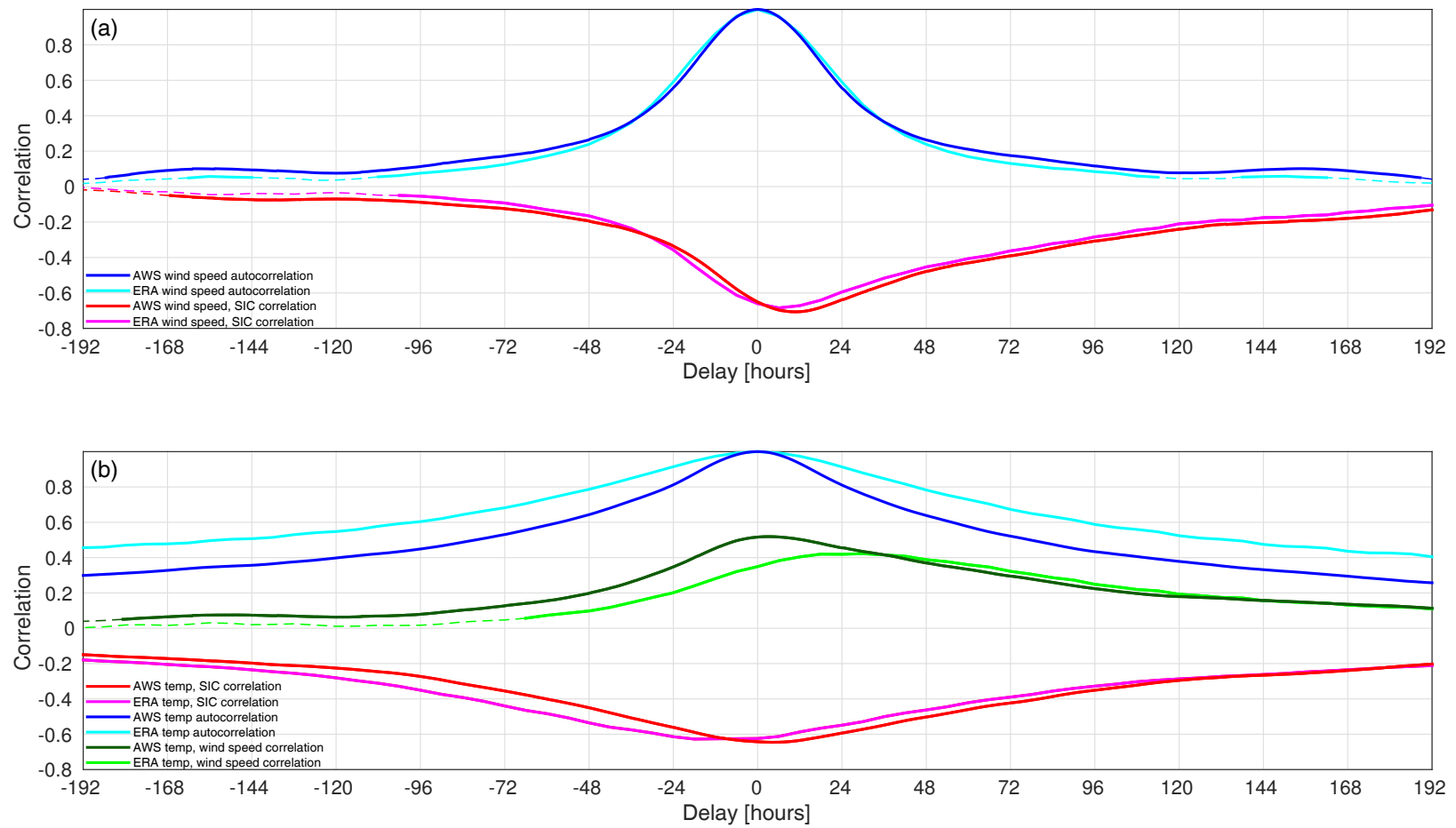

Figure 4. (a) Cross-correlation curve for sea ice concentration and AWS (red) and ERA-Interim (magenta) wind speeds and autocorrelation curve for wind speed at Laurie II AWS (blue) and ERA-Interim (cyan). (b) Cross-correlation curve for sea ice concentration and temperature for AWS (red) and ERA-Interim (magenta); autocorrelation curves for wind speed at Laurie II AWS site (blue) and ERA-Interim (cyan) are also shown. Cross correlation for wind speed and temperature measured at Laurie II AWS (dark green) and ERA-Interim (light green). Dashed lines indicate significance $p>0.01$. The delay is defined such that positive indicates meteorology measures leading SIC.

wind speed. With the exception of a short period in the medium case, spanning -30 to $6 \mathrm{~h}$, when weak positive correlations were observed. The medium case has a correlation extrema of -0.5 at $30 \mathrm{~h}$, while the extrema for the low case is -0.4 at $50 \mathrm{~h}$ between AWS and SIC data. Both these values are significantly weaker and later than those of both the high and total cases. This could be because weaker wind speeds will not have as significant of an effect on sea ice, causing any advection of sea ice and subsequent sea ice break up to occur much less rapidly than the high-wind case. Another possible cause is that the higher wind speeds within each class are more likely to increase to stronger cases after the classified period, causing a decrease in SIC at a large delay. Due to the autocorrelation for both medium and low cases being very low at their respective times of extrema, the former explanation seems unlikely since there would be little coherence between wind speed at $0 \mathrm{~h}$ and wind speed at the extrema.

The categorized autocorrelation curves found using the ERA-interim virtual station are not as perfectly symmetrical as those for the AWS data. This is due to sampling issues that occur at the beginnings and ends of the broken time series, obtained because of the wind speed classifications used. These sampling issues are also present in the AWS autocorrelation curves but are of greater significance when using the low-temporal-resolution ERA-interim data. The medium ERA-interim wind speed autocorrelation curve shows persistence similar to that of the low and high cases, differing from that of AWS, which showed a much shorter persistence in the medium case. In the low-wind case, $\mathrm{CCF}$ of wind speed versus SIC derived from ERA-interim output is very similar to that found using AWS. In contrast, the ERA-interim CCFs in the medium- and high-wind-speed cases differ significantly from those of AWS. In particular, the ERA-interim medium case displays stronger negative correlations than that of the AWS between -24 and $24 \mathrm{~h}$, after which the two are very similar. The high-wind regime for ERA-Interim displays significantly weaker correlations between -12 and $72 \mathrm{~h}$ than the corresponding pattern derived using AWS data. The latter point likely reflects the fact that the ERA-Interim data are generally poor at representing the strength of the wind in the strong-wind-speed periods for this region, this being supported by the large gradient derived (1.70) when applying a linear least squares regression to the ERA-Interim and AWS wind speeds.

\subsection{SIC anomalies during extreme wind events}

To gain a greater understanding of the influence of winds on SIC in the region, we now consider the spatial structure of 

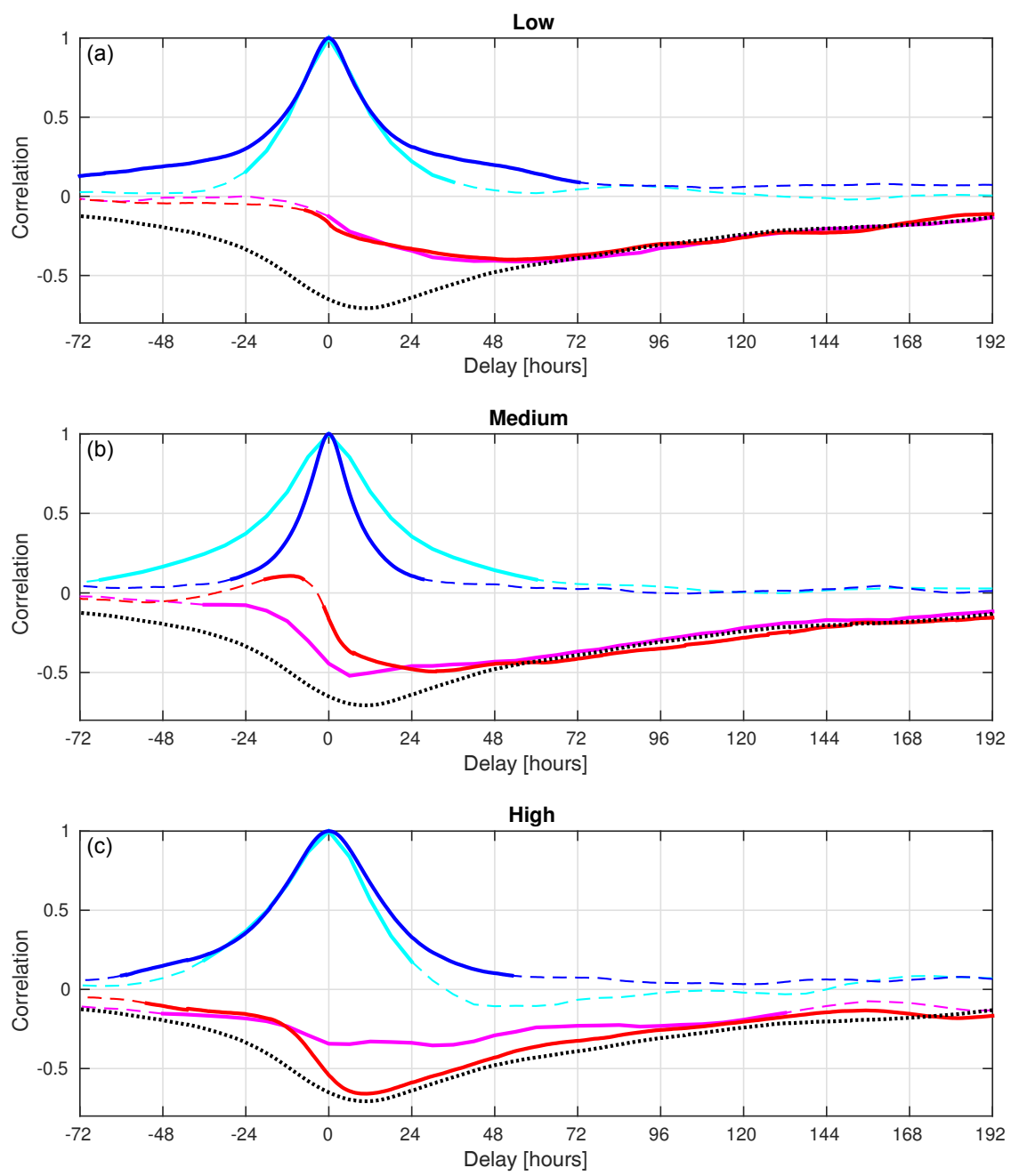

Figure 5. Cross-correlation curves for SIC and AWS (red) and ERA-Interim (magenta) wind speeds at the Laurie II AWS site for periods of low (a), medium (b) and high (c) winds. Wind autocorrelation curves for low-, medium- and high-wind cases from AWS (blue) and ERA-Interim (cyan). Dashed lines indicate significance $p>0.01$. The dotted black line represents the cross-correlation curve for the total of all wind cases for comparison.

the SIC anomalies for the high- and low-wind classes previously identified for different periods relative to the onset of those classes. For both low- and high-wind classes, the April to October mean bootstrap SIC anomaly for each pixel in the Ross Sea region was calculated over the 2001-2014 period (defined by Laurie II AWS coverage) (Fig. 6). Composites for several days of delay before and after the wind event onset were then derived to highlight how the sea ice anomaly varies spatially prior to and following these wind classes. Histograms are also shown to indicate how the distribution of each wind class changes throughout the period examined. On day zero all cases are either $100 \%$ high or low winds, but on following days the winds are not classified. This allows the persistence of these wind events to be observed. We find significant, positive anomalies within the Ross Sea polynya during low winds and negative anomalies during high winds in general (Fig. 6). No significant anomalies were found during the medium-wind cases and these are therefore not displayed. All significant anomalies found occur within known polynyas; this is likely because sea ice is generally thinner and has a lower concentration within polynyas. Significant anomalies are observed 2 days before the measured wind and remain until 5 days after. An imbalance in the proportions of the three wind classes (indicated by the inset histograms) also remains for a similar period. The CCF of SIC versus wind speed displayed increase and decrease $e$-folding times of -48 and $100 \mathrm{~h}$ (Fig. 4). Thus, during a high-wind event the period where SIC is decreasing seems to be significantly impacted by advection. 

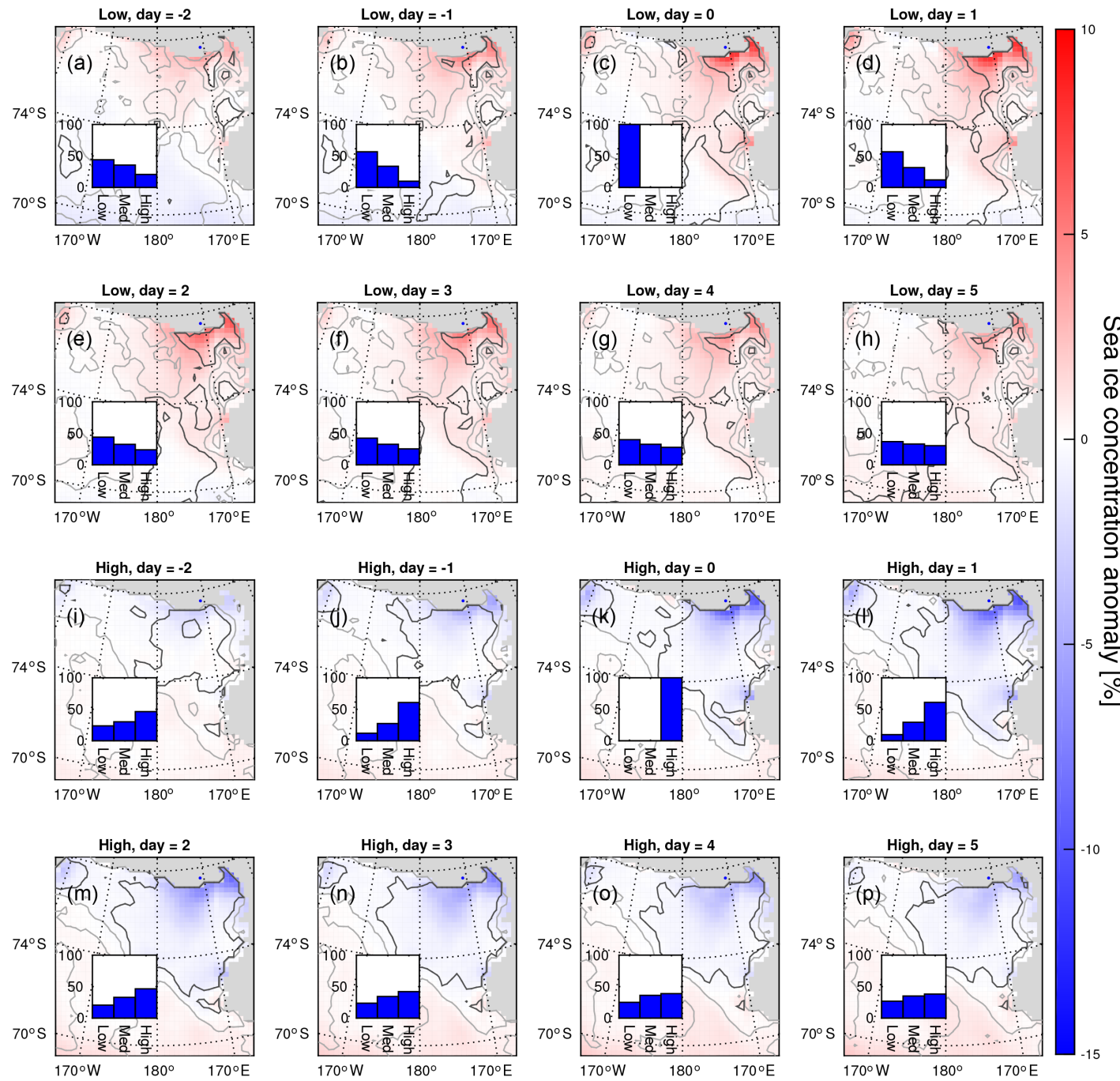

Figure 6. Composites of 2000-2014 sea ice concentration anomaly at varying delay for low-wind cases (a-h) and high-wind cases (i-p). The grey and black contours indicate 80 and $99 \%$ significance, respectively. The inset histograms indicate the percentage of the three wind cases that occur at the respective delay.

\subsection{Sea ice motion anomalies during extreme wind events}

The mean sea ice motion vectors for April-October 2001 until 2014 (Fig. 7) show northward flow throughout the Ross Sea, with an easterly component occurring to the east of Cape Adare. This highlights the net export of sea ice from the north-facing coasts of the Ross Sea throughout this period (Comiso et al., 2011). Composites of sea ice motion anomalies related to high- and low-wind states at delays varying from -2 to 3 days from the wind event are displayed in Fig. 8. During periods of low wind speed at Laurie II, anticyclonic anomalies occur throughout the Ross Sea (Fig. 8af). Conversely, cyclonic anomalies are found during periods of high winds at Laurie II (Fig. 8g-1). These anomalies are largest at zero lag but persist for $24 \mathrm{~h}$ after the wind event, with weak anomalies being found in both low and high states $48 \mathrm{~h}$ after the wind event. It is also noticeable that no coherent pattern in the sea ice anomalies associated with the mediumwind state are observed (not shown). The cyclonic anomalies during strong wind events and anticyclonic anomalies during low-wind events highlight the critical influence of atmospheric near-surface winds on sea ice motion in the region.

\section{Discussion}

Bromwich et al. (1998) found annual correlations between SIC in the RSP and wind speed at the Ferrell AWS for 19881991 ranging from -0.3 to -0.52 . We found the multiyear correlation for SIC in the RSP and wind speed at the Ferrell AWS from 2001 to 2014 to be -0.67 . Bromwich et al. (1998) used a RSP area that extended significantly further 


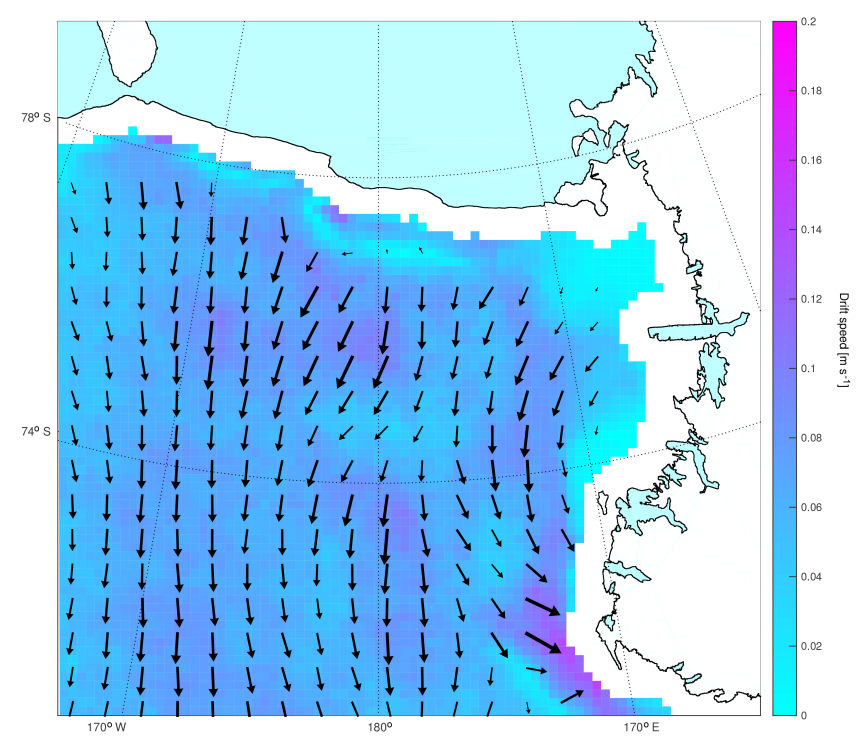

Figure 7. Mean sea ice motion vectors in the Ross Sea region. Arrows indicate the mean sea ice drift vector over a $100 \times 100 \mathrm{~km}$ region. The color scale indicates the magnitude of this vector field.

from the shore than the one used in our analysis. Winds over the Bromwich RSP area were not as well represented by the Ferrell AWS, explaining the weaker correlations. We found a minimum correlation between Ferrell wind speed and SIC to be -0.72 at a $10 \mathrm{~h}$ delay; Bromwich et al. (1998) did not calculate correlations at varying delay, making comparison with this value impossible. Bromwich et al. (1998) also found correlations between SIC and inverse temperature ranging between 0.44 and 0.55 . We found a correlation of 0.64 between SIC and inverse temperature; this difference is due to the different RSP area and time periods used.

ERA-Interim was able to generate wind speeds that correlated well with those of several AWS sites, indicating that the relative wind speeds within ERA-Interim were consistent with the AWS measurements. However, at AWS sites near significant topography, ERA-Interim was found to predict wind speeds significantly weaker than the winds measured by the AWS, with slopes of the regression lines of 1.70 and 1.52 (implying that the ERA-Interim values are this factor smaller than the AWS measurement) at the Laurie II and Ferrell sites, respectively (Fig. 3). This is likely because ERA-Interim is unable to accurately model the mesoscale barrier affect of Ross Island and the resulting flow convergence. This hypothesis is supported by recent comparisons between AWS data and mesoscale model output in the region (Jolly et al., 2016). The CCF of wind speed versus SIC produced using the virtual Laurie station was very similar to that found using the Laurie AWS data. However, when the data were separated into low-, medium- and high-wind regimes, based on a categorization derived from the AWS data, significant differences were found between the ERA-Interim and AWS CCFs. This suggests that the ERA-Interim output provides a good repre- sentation of the occurrence of the different wind states, but the magnitudes from the ERA-Interim underestimate the values observed by AWS. This indicates that ERA-Interim output is not be a reliable way to identify relevant wind thresholds used in models simulating polynya dynamics. This factor makes the usage of ERA-Interim problematic for polynya studies since they generally form on coastlines near topography in Antarctica. ERA-Interim provides $10 \mathrm{~m}$ wind speeds, while the AWS wind speeds are measured at 2-3 m (Lazzara et al., 2012; Dee et al., 2011). This would suggest that a scale factor exists between the two data sets, an effect that was not corrected. While this will not affect the correlation comparisons performed, it may explain the scale factors observed. However, this small height difference is not able to explain the large-scale factors found, indicating that topography must have a significant effect.

Sea ice motion vector anomaly composites indicate that wind-driven sea ice drift is significant $12 \mathrm{~h}$ before through to $36 \mathrm{~h}$ after strong wind events peak. This coincides with the peak cross correlation between SIC and wind speed, indicating that during a strong wind event, SIC within the RSP is at a minimum during the period where wind-driven sea ice drift is found to be significant. Following strong wind events, significant negative SIC anomalies are also found and persist for up to 5 days after the event. This period is longer than the persistence of most strong wind events (see autocorrelation in Figs. 4 and 5), and it therefore seems unlikely that the SIC recovery following strong wind events is controlled by wind-driven advection of sea ice. Thus, the recovery of sea ice is likely dominated by formation of new sea ice within the RSP rather than advection of existing sea ice, an assumption supported by recent analysis detailed in Nakata et al. (2015). During periods of high wind, negative SIC anomalies were found within the Ross Sea polynya. Similarly, positive anomalies were found during periods of low wind. The significant anomalies were also only found within areas of known polynyas, likely due to thinner, less concentrated sea ice being present within the polynyas. Correlations between wind speed and SIC were significantly stronger for the high-wind class than the two weaker classes (Fig. 5), indicating that the wind-driven polynya mechanism is driven by the strongest wind speeds and moderate winds have a less significant effect.

The wind stress on sea ice depends on the square of the wind speed. This does not however result in a linear relationship between SIC and the square of the wind speed because wind stress only defines the force causing the advection. For this reason wind speed was correlated with SIC rather than the square of wind speed. Only wind speed was considered in this study; therefore northerly winds were not distinguished from southerly winds, even though they would have a vastly different effect on polynyas. Coggins et al. (2014) found that the majority of wind measurements in the northwestern RIS fall within the southwestern quadrant due to the dominance of katabatic-fed drainage and barrier flows related to the 

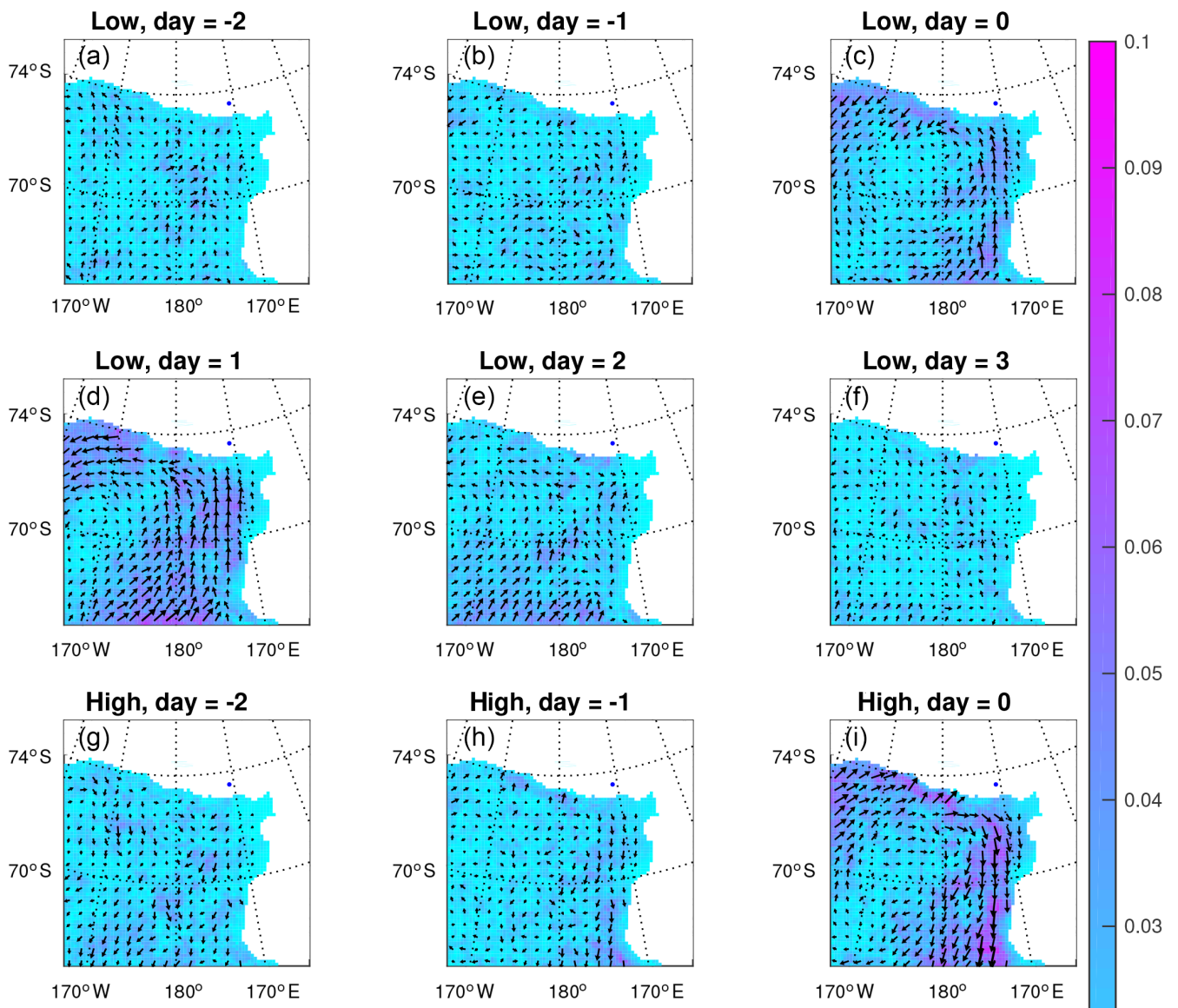

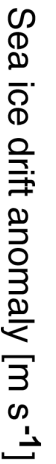
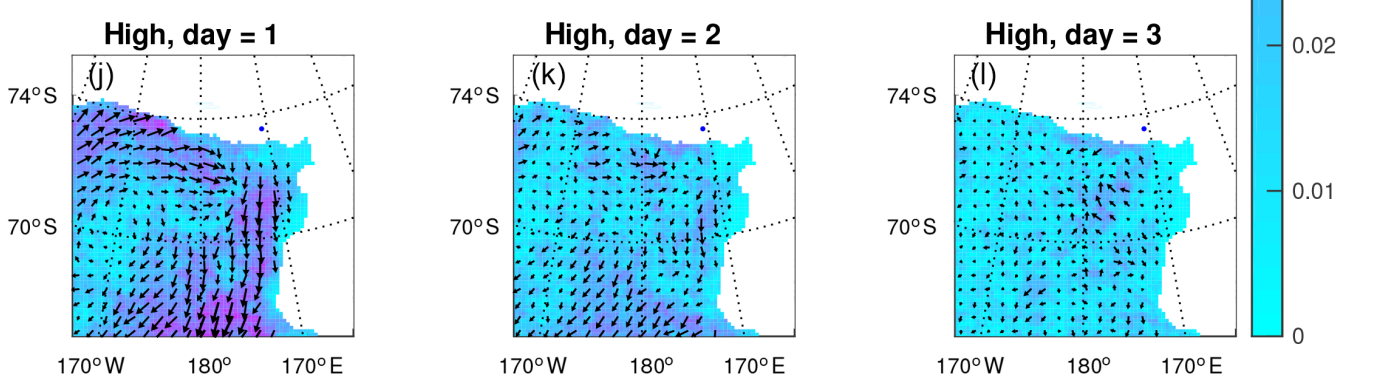

Figure 8. (a-f) Sea ice motion anomalies for days -2 to 3 for low-wind events. (g-l) Sea ice motion anomalies for days -2 to 3 for high-wind events. Composites are formed over the 2000-2014 period.

Transantarctic Mountains and a semi-persistent low-pressure system east of the Ross Sea. This was also identified in detail analysis around the Laurie II region presented in Jolly et al. (2016). This directional bias becomes even stronger when only the largest wind speeds are considered. This means that errors due to northerly winds are minimal in our analysis.

Only the results obtained from weather data taken at Laurie II are presented in this study because of its proximity to the RSP. However, a similar set of analyses were performed for the Vito, Emilia, and Ferrell AWS sites. These produced similar results, with the only significant difference being that weaker correlations were found at these sites when compared to those with Laurie II. This is hypothesized to be because these sites are based further inland, and are therefore more distant from the center of the RSP than Laurie II. This would mean that the winds at these locations would be less representative than those at Laurie II.

Due to lack of weather data available within the RSP, AWS data from sites on the nearby Ross Ice Shelf were assumed to be representative of that over the RSP. A multitude of effects will cause the actual winds and temperatures over the RSP differ somewhat from those measured at the Laurie II AWS site. These effects will be inhomogeneous across the RSP. Proximity to topography, particularly Ross Island, differs between the RSP and Laurie II. Southerly katabatic drainage flows will accelerate around Ross Island, causing stronger 
winds to be observed within the RSP. Meanwhile, other areas of the RSP north of Ross Island will be somewhat sheltered from many of the predominant southerly winds. Due to the relatively warm ocean, an upward heat flux will occur within the RSP when open water or thin ice is present. This will cause an increase in surface air temperatures over the RSP. This effect will not occur at Laurie II due to the insulation of the thick ice shelf. Due to the lack of measurements within the RSP, the net result of these effects is unidentifiable.

When within $50 \mathrm{~km}$ of the coastline, the sea ice motion vectors used in this study are biased. This coastal area coincides with the majority of polynya activity and therefore the dynamic effects of changing wind speeds were not able to be observed directly within the RSP. The assumption is made that offshore sea ice drift will be representative of drift in coastal polynyas. Although derived sea ice motion is coherent throughout the Ross Sea, the motion within coastal polynyas may be different since thinner, less concentrated ice exists within coastal polynyas.

The bootstrap SIC data used throughout this study use passive microwave measurements to calculate SIC. The microwave signature for a thin sheet of ice can be identical to that of scattered thick ice. For sea ice thickness less than $10 \mathrm{~cm}$, the bootstrap sea ice concentration is a function of sea ice thickness (Kwok et al., 2007). During periods of low wind speed, bootstrap SIC within the RSP often reaches $100 \%$, indicating a continuous covering sheet of sea ice with thickness greater than $10 \mathrm{~cm}$. During a strong wind event, the SIC decreases via dynamic processes, leaving areas of open water with scattered, likely thick ice. As freezing of the open water occurs, a layer of thin ice will form, causing a gradual increase in the bootstrap SIC. As this sea ice thickens, the heat flux between the warmer ocean and the cooler atmosphere will decrease, causing the rate of freezing to also decrease. Because both bootstrap SIC and the rate of freezing within a polynya depend on the thermal conductivity of the sea ice, the bootstrap SIC may actually provide a more meaningful measure of sea ice production within polynyas than true SIC values.

Despite the length of the bootstrap SIC time series, we were unable to identify any significant trends in polynya activity. This may be due to changing polynya structure as a result of calving from the Ross Ice Shelf and the ice shelf gradually advancing northward. As the coastline evolves, so does the RSP. This causes issues since the land mask for bootstrap SIC data does not change with time. Over long periods, a changing amount of the RSP is visible in the bootstrap SIC data, causing biases in any metric for polynya activity. This effect was particularly obvious in 2005 when iceberg B15 calved from the Ross Ice Shelf, moving a $300 \mathrm{~km}$ long section of the northern coastline $40 \mathrm{~km}$ further south.

\section{Conclusions}

During the austral winter, strong negative correlations were found between AWS wind speeds and SIC in the RSP. In contrast to previous studies, we examined these correlations as a function of lag and found that they persisted for several days and exceeded the persistence of the wind speed autocorrelation. When the data were split into low-, medium- and high-wind cases and correlations were calculated from the separate data sets, the high-wind states displayed stronger correlations than the other two states, indicating that stronger winds had the most significant impact on sea ice within the RSP. This analysis was repeated using a virtual AWS site interpolated from ERA-Interim reanalysis wind fields. It was found that although strong correlations existed between the AWS and ERA-Interim wind speeds, a linear scale factor, significantly greater than 1 was present at AWS sites in close proximity to topography. Wind speeds measured at the Laurie II AWS correlated strongly with colocated ERA-Interim wind speeds, but a scale factor of 1.70 (indicating AWS wind speeds were 1.70 times faster than ERA-Interim wind speeds) was found. The ERA-Interim wind speeds were used to calculate a wind speed against SIC CCF that agreed with the CCF formed using AWS wind speeds. However, when the data set was categorized into low-, medium- and high-wind cases and individual CCFs were calculated, significant differences from the AWS CCFs were found in the high-wind state. Likely due to the effects of nearby small-scale topography, ERA-Interim wind speeds were unable to reproduce the relationships found between AWS wind speeds and SIC in the RSP. This difference has implications for interpreting sea ice anomalies using ERA-Interim winds in regions close to complex topography.

For low-, medium- and high-wind states measured at Laurie II, AWS composites of SIC were made. During periods of low wind speed $\left(<3.5 \mathrm{~ms}^{-1}\right)$, significant positive SIC anomalies that persisted for 5 days after the wind event were found within the RSP. Conversely, significant negative SIC anomalies that persisted for 5 days after the wind event were found within the RSP during periods of high wind speed $\left(>7.5 \mathrm{~ms}^{-1}\right)$. No significant anomalies were found during medium-wind-speed periods. Significant SIC anomalies were only found to occur in coastal areas where polynya are known to occur. Composites of sea ice motion vectors were also calculated for these wind states. During periods of high-wind cyclonic motion, anomalies were found throughout the Ross Sea, while anticyclonic anomalies were found during periods of low wind. These sea ice motion anomalies were found to persist for $48 \mathrm{~h}$ after the wind event. SIC anomalies persisted several days longer than sea ice motion anomalies. This suggests that following a strong-wind event, polynyas reform sea ice through thermodynamic, rather than advective processes, resulting in increased sea ice production within polynyas following strong-wind events. This implies that changes of winds in this region would have significant 
impacts on polynya processes, potentially strongly impacting coastal sea ice production. This study shows that coarse resolution atmospheric reanalysis data would not capture the correct magnitude of this effect.

\section{Data availability}

Due to their large size, the sea ice motion vectors used in this study are available upon request.

The AWS data used were accessed via http://amrc.ssec.wisc.edu/aws/index.php?region=

RossIslandVicinity\&station=Laurie0II (Lazzara et al., 2012).

The Bootstrap SIC data used were accessed via the NSIDC website (https://nsidc.org/data/NSIDC-0079/ versions/2\#) (Comiso et al., 2008).

Acknowledgements. We would like to thank the support of the University of Wisconsin-Madison Automatic Weather Station Program for the AWS observational data set (NSF grant numbers ANT-0944018, ANT-1245663, ANT-0943952 and ANT-1245737). We would also like to acknowledge the NSIDC for the provision of the SSM/I data set. This work was partially funded by a grant from the New Zealand Antarctic Research Institute, scholarships from both the Department of Physics and Astronomy at the University of Canterbury and NZ Post (administered by Antarctica New Zealand).

Edited by: C. Haas

Reviewed by: three anonymous referees

\section{References}

Bintanja, R., van Oldenborgh, G. J., Drijfhout, S. S., Wouters, B., and Katsman, C. A.: Important role for ocean warming and increased ice-shelf melt in Antarctic sea-ice expansion, Nat. Geosci., 6, 376-379, doi:10.1038/ngeo1767, 2013.

Bromwich, D., Liu, Z., Rogers, A. N., and Van Woert, M. L.: Winter atmospheric forcing of the Ross Sea Polynya, in: Ocean, ICE, Atmos. Interact. Antarct. Cont. MARGIN, vol. 75, 101-133, American Geophysical Union, doi:10.1029/AR075p0101, 1998.

Brümmer, B. and Hoeber, H.: A mesoscale cyclone over the Fram Strait and its effects on sea ice, J. Geophys. Res.-Atmos., 104, 19085-19098, doi:10.1029/1999JD900259, 1999.

Brümmer, B., Schröder, D., Müller, G., Spreen, G., JahnkeBornemann, A., and Launiainen, J.: Impact of a Fram Strait cyclone on ice edge, drift, divergence, and concentration: Possibilities and limits of an observational analysis, J. Geophys. Res., 113, C12003, doi:10.1029/2007JC004149, 2008.

Coggins, J., McDonald, A. J., Plank, G., Pannell, M., Jolly, B., Parsons, S., and Delany, T.: SNOW-WEB: a new technology for Antarctic meteorological monitoring, Antarct. Sci., 25, 583-599, doi:10.1017/S0954102013000011, 2013.

Coggins, J. H. J., McDonald, A. J., and Jolly, B.: Synoptic climatology of the Ross Ice Shelf and Ross Sea region of Antarctica: $\mathrm{k}$-means clustering and validation, Int. J. Climatol., 34, 23302348, doi:10.1002/joc.3842, 2014.
Comiso, J. C.: Bootstrap Sea Ice Concentrations from Nimbus-7 SMMR and DMSP SSM/I-SSMIS, Version 2., Boulder, Color. USA. NASA Natl. Snow Ice Data Cent. Distrib. Act. Arch. Center., doi:10.5067/J6JQLS9EJ5HU, 2000.

Comiso, J. C. and Nishio, F.: Trends in the sea ice cover using enhanced and compatible AMSR-E, SSM/I, and SMMR data, J. Geophys. Res., 113, C02S07, doi:10.1029/2007JC004257, 2008.

Comiso, J. C., Kwok, R., Martin, S., and Gordon, A. L.: Variability and trends in sea ice extent and ice production in the Ross Sea, J. Geophys. Res., 116, C04021, doi:10.1029/2010JC006391, 2011.

Dee, D. P., Uppala, S. M., Simmons, A. J., Berrisford, P., Poli, P., Kobayashi, S., Andrae, U., Balmaseda, M. A., Balsamo, G., Bauer, P., Bechtold, P., Beljaars, A. C. M., van de Berg, L., Bidlot, J., Bormann, N., Delsol, C., Dragani, R., Fuentes, M., Geer, A. J., Haimberger, L., Healy, S. B., Hersbach, H., Hólm, E. V., Isaksen, L., Kållberg, P., Köhler, M., Matricardi, M., McNally, A. P., Monge-Sanz, B. M., Morcrette, J.-J., Park, B.-K., Peubey, C., de Rosnay, P., Tavolato, C., Thépaut, J.-N., and Vitart, F.: The ERA-Interim reanalysis: configuration and performance of the data assimilation system, Q. J. Roy. Meteor. Soc., 137, 553-597, doi:10.1002/qj.828, 2011.

Drucker, R., Martin, S., and Kwok, R.: Sea ice production and export from coastal polynyas in the Weddell and Ross Seas, Geophys. Res. Lett., 38, L17502, doi:10.1029/2011GL048668, 2011.

Emery, W. J., Fowler, C. W., and Maslanik, J. A.: Satellite-derived maps of Arctic and Antarctic sea ice motion: 1988 to 1994, Geophys. Res. Lett., 24, 897-900, doi:10.1029/97GL00755, 1997.

Heil, P., Fowler, C., and Lake, S.: Antarctic sea-ice velocity as derived from SSM/I imagery, Ann. Glaciol., 44, 361-366, doi:10.3189/172756406781811682, 2006.

Holland, P. R.: The seasonality of Antarctic sea ice trends, Geophys. Res. Lett., 41, 4230-4237, doi:10.1002/2014GL060172, 2014.

Holland, P. R. and Kwok, R.: Wind-driven trends in Antarctic seaice drift, Nat. Geosci., 5, 1-8, doi:10.1038/ngeo1627, 2012.

Jolly, B., McDonald, A. J., Coggins, J. H. J., Cassano, J., Lazzara, M., Zawar-Reza, P., Graham, G., Plank, G., Petterson, O., and Dale, E.: A validation of the Antarctic Mesoscale Prediction System using Self-Organizing Maps and high density observations from SNOWWEB, Mon. Weather Rev., 144, 3181-3200, doi:10.1175/MWR-D-15-0447.1, 2016.

Kwok, R. and Comiso, J. C.: Spatial patterns of variability in Antarctic surface temperature: Connections to the Southern Hemisphere Annular Mode and the Southern Oscillation, Geophys. Res. Lett., 29, 50-1-50-4, doi:10.1029/2002GL015415, 2002.

Kwok, R., Comiso, J. C., Martin, S., and Drucker, R.: Ross Sea polynyas: Response of ice concentration retrievals to large areas of thin ice, J. Geophys. Res., 112, C12012, doi:10.1029/2006JC003967, 2007.

Lazzara, M. A., Weidner, G. A., Keller, L. M., Thom, J. E., and Cassano, J. J.: Antarctic Automatic Weather Station Program: 30 Years of Polar Observation, B. Am. Meteorol. Soc., 93, 15191537, doi:10.1175/BAMS-D-11-00015.1, 2012.

Liu, H., Jezek, K., Li, B., and Zhao., Z.: Radarsat Antarctic Mapping Project Digital Elevation Model, Version 2., Boulder, Color. USA. NASA Natl. Snow Ice Data Cent. Distrib. Act. Arch. Center., 2001.

Mårtensson, S., Meier, H. E. M., Pemberton, P., and Haapala, J.: Ridged sea ice characteristics in the Arctic from a coupled multi- 
category sea ice model, J. Geophys. Res.-Ocean., 117, C00D15, doi:10.1029/2010JC006936, 2012.

Maslanik, J. and Stroeve, J.: DMSP SSM/I-SSMIS Daily Polar Gridded Brightness Temperatures, Version 4., Boulder, Colorado USA. NASA National Snow and Ice Data Center Distributed Active Archive Center, doi:10.5067/AN9AI8EO7PX0, 2004.

Nakata, K., Ohshima, K. I., Nihashi, S., Kimura, N., and Tamura, T.: Variability and ice production budget in the Ross Ice Shelf Polynya based on a simplified polynya model and satellite observations, J. Geophys. Res.-Ocean., 120, 6234-6252, doi:10.1002/2015JC010894, 2015.

Nicolas, J. P. and Bromwich, D. H.: New Reconstruction of Antarctic Near-Surface Temperatures: Multidecadal Trends and Reliability of Global Reanalyses, J. Climate, 27, 8070-8093, doi:10.1175/JCLI-D-13-00733.1, 2014.

Ohshima, K. I., Fukamachi, Y., Williams, G. D., Nihashi, S., Roquet, F., Kitade, Y., Tamura, T., Hirano, D., HerraizBorreguero, L., Field, I., Hindell, M., Aoki, S., and Wakatsuchi, M.: Antarctic Bottom Water production by intense sea-ice formation in the Cape Darnley polynya, Nat. Geosci., 6, 235-240, doi:10.1038/ngeo1738, 2013.

Parish, T. R. and Bromwich, D. H.: Reexamination of the NearSurface Airflow over the Antarctic Continent and Implications on Atmospheric Circulations at High Southern Latitudes, Mon. Weather Rev., 135, 1961-1973, doi:10.1175/MWR3374.1, 2007.

Parish, T. R., Cassano, J. J., and Seefeldt, M. W.: Characteristics of the Ross Ice Shelf air stream as depicted in Antarctic Mesoscale Prediction System simulations, J. Geophys. Res., 111, D12109, doi:10.1029/2005JD006185, 2006.

Powers, J. G., Manning, K. W., Bromwich, D. H., Cassano, J. J., and Cayette, A. M.: A Decade of Antarctic Science Support Through Amps, B. Am. Meteorol. Soc., 93, 1699-1712, doi:10.1175/BAMS-D-11-00186.1, 2012.
Reddy, T. E., Arrigo, K. R., and Holland, D. M.: The role of thermal and mechanical processes in the formation of the Ross Sea summer polynya, J. Geophys. Res., 112, C07027, doi:10.1029/2006JC003874, 2007.

Sen Gupta, A. and England, M. H.: Coupled Ocean-AtmosphereIce Response to Variations in the Southern Annular Mode, J. Climate, 19, 4457-4486, doi:10.1175/JCLI3843.1, 2006.

Stammerjohn, S. E., Martinson, D. G., Smith, R. C., Yuan, X., and Rind, D.: Trends in Antarctic annual sea ice retreat and advance and their relation to El Niño - Southern Oscillation and Southern Annular Mode variability, J. Geophys. Res., 113, C03S90, doi:10.1029/2007JC004269, 2008.

Tamura, T., Ohshima, K. I., and Nihashi, S.: Mapping of sea ice production for Antarctic coastal polynyas, Geophys. Res. Lett., 35, L07606, doi:10.1029/2007GL032903, 2008.

Turner, J., Comiso, J. C., Marshall, G. J., Lachlan Cope, T. A., Bracegirdle, T., Maksym, T., Meredith, M. P., Wang, Z., and Orr, A.: Non annular atmospheric circulation change induced by stratospheric ozone depletion and its role in the recent increase of Antarctic sea ice extent, Geophys. Res. Lett., 36, L08502, doi:10.1029/2009GL037524, 2009.

Turner, J., Hosking, J. S., Bracegirdle, T. J., Marshall, G. J., and Phillips, T.: Recent changes in Antarctic Sea Ice, Philos. T. Roy. Soc. A, 373, 20140163, doi:10.1098/rsta.2014.0163, 2015.

Whitworth, I. and Orsi, A. H.: Antarctic Bottom Water production and export by tides in the Ross Sea, Geophys. Res. Lett., 33, 1-4, doi:10.1029/2006GL026357, 2006. 